\title{
Diabetes: A review of awareness, comorbidities, and quality of life in India
}

Balasaheb Bansode, Rangasamy Nagarajan

Department of Development Studies, International Institute for Population Sciences, Mumbai, Maharashtra, India

\begin{abstract}
Diabetes is one of the major contributors for the noncommunicable diseases. The disease burden due to diabetes is huge, and it not only puts pressure on the diabetes patients but also it adds pressure on the economy of the developing and underdeveloped nations. In India, the burden due to diabetes is more important as every fifth person is a diabetic. This paper reviews awareness and source of knowledge of diabetes, awareness about risk factors, and complications of diabetes in India. The review reveals that (a) awareness about diabetes is less in India; (b) awareness regarding specific risk factors associated with diabetes (obesity, tobacco use, alcohol consumption, and high blood pressure) is found to be less; (c) there is a negative association between duration of diabetes and health-related quality of life; and (d) microvascular complications (retinopathy, nephropathy, neuropathy, and coronary diseases) are major comorbidities affecting the diabetes patients. The review reveals that it is imperative to work effectively toward implementing a holistic program for diabetes prevention by ensuring proper awareness in the community.
\end{abstract}

Keywords: Awareness, comorbidities, diabetes, India, quality of life

Address for correspondence: Mr. Balasaheb Bansode, International Institute for Population Sciences, Mumbai - 400088 , Maharashtra, India. E-mail: bansodebalasaheb7@gmail.com

Received: 07.02.2017, Accepted: 02.05.2017

\section{INTRODUCTION}

Despite the high global burden of mortality and morbidity from noncommunicable diseases (NCDs), the response has not been strong from the governments. In 2012, 67\% of global deaths (i.e., 38 million of the 56 million global deaths) resulted from NCDs, principally cardiovascular diseases (CVDs), diabetes, cancers, and chronic respiratory diseases. Nearly $73 \%$ (28 million) of these deaths occurred in low- and middle-income countries. ${ }^{[1]} \mathrm{NCDs}$ account for nearly half of all deaths in India. CVDs, cancer, diabetes, chronic obstructive lung disease, mental disorders, and injuries are the main causes of death and disability due to NCDs. Unless interventions are made to prevent and

\begin{tabular}{|l|l|}
\hline \multicolumn{2}{|c|}{ Access this article online } \\
\hline Quick Response Code: & Website: \\
\hline & www.joshd.net \\
\cline { 2 - 2 } & DOI: \\
& 10.4103/joshd.J_Soc_Health_ \\
\hline
\end{tabular}

control NCDs, their burden is likely to increase substantially in the future. Considering the high cost of medicines and longer duration of treatment, NCDs constitute a greater financial burden to low-income groups. ${ }^{[2]}$

In the first phase of the first-ever national diabetes study carried out in India in the recent past, it has been estimated that in 2011, there would be 62.4 million people with diabetes and another 77.2 million with prediabetes. ${ }^{[3]}$ The burden of diabetes is huge and continues to put pressure on the economy of the developing and underdeveloped nations. In India, this is more important as every fifth person is a diabetic. ${ }^{[3]}$ According to NSSO $60^{\text {th }}$ round 2004,

This is an open access article distributed under the terms of the Creative Commons Attribution-NonCommercial-ShareAlike 3.0 License, which allows others to remix, tweak, and build upon the work non-commercially, as long as the author is credited and the new creations are licensed under the identical terms.

For reprints contact: reprints@medknow.com

How to cite this article: Bansode B, Nagarajan R. Diabetes: A review of awareness, comorbidities, and quality of life in India. J Soc Health Diabetes 2017;5:77-82. 
twenty persons were hospitalized due to diabetes per 1000 persons per year in India. ${ }^{[4]}$ India is one of the top ten diabetic countries in the world with 31.7 million diabetic people in the year 2002 and World Health Organization (WHO) has estimated that it will increase to 79.4 million in $2030 .{ }^{[5]}$

The WHO has estimated that, in India, CVDs and diabetes mortality accounted for 3.8 lakh and 2.8 lakh deaths, respectively, in the year 2008. ${ }^{[6]}$ In view of higher and increasing prevalence of diabetes in Indian society, this paper reviews the awareness and health-care practices among diabetic patients, comorbidities associated with diabetes, and quality of life of people with diabetes in India. The available studies in the context of India and other developing countries are reviewed. Studies from developed countries are also taken into account, wherever necessary.

\section{Types of diabetes}

There are two types of diabetes: Type 1 and Type 2. Type-1 diabetes, previously called insulin-dependent diabetes mellitus (IDDM), accounts for $5 \%-10 \%$ of all diagnosed cases of diabetes. Risk factors such as autoimmune, genetic, and environmental factors are involved in the development of this type of diabetes. Type 2 diabetes, previously called non-IDDM, accounts for about $90 \%-95 \%$ of all diagnosed cases of diabetes. Risk factors for Type 2 diabetes include older age, obesity, family history of diabetes, prior history of gestational diabetes, impaired glucose tolerance, and physical inactivity.

\section{AWARENESS AND HEALTH-CARE PRACTICES OF DIABETIC PATIENTS}

\section{Source of awareness}

Awareness and health-care practices are important for understanding the reason behind diabetes and prevention of diabetes. The knowledge about prevention of diabetes increases with increase in the level of education. Researchers have emphasized the need for more continuing medical education programs on diabetes for doctors and also for developing a cadre of diabetes educators in developing countries to regulate better diabetes education imparted to patients to expand the awareness of diabetes at community level. ${ }^{[7]}$ Researchers have also focused on developing the awareness through mass media and print media for dissemination of information of diabetes. It is believed that the internet will become an important source of health-care information. The important role of television, radio, SMS, hotline, cinema halls, and newspaper for prevention of diabetes severity is also highlighted. ${ }^{[8]}$ The response was found to be highest among the general public when the diabetes awareness camps were organized in common places such as community halls, parks beaches, bus stands, railway stations, community and marriage halls, open grounds, and supermarkets in addition to roadside programs in the early morning hours. ${ }^{[9]}$ Studies have suggested the following measures for effective spread of awareness of diabetes: disease management programs, trained peers and community health workers, community-based programs, use of technology, continuous education and support groups, and medical nutrition therapy. ${ }^{[10]} \mathrm{It}$ is also suggested that physician should communicate the following to the patients for diabetes prevention: instruction in urine testing, weight control, foot care, and use of medication. ${ }^{[11]} \mathrm{A}$ major research project on prevention, awareness, counseling, and evaluation (PACE) of diabetes carried out in Chennai recommends healthy diets, obesity prevention, and physical activity for diabetes prevention programs. The researchers of the project suggested that for the very high successful awareness program, free blood sugar tests should be offered to the public and this is a major attraction for getting people to attend awareness programs. ${ }^{[12]}$ The British Diabetic Association study suggests that diabetes awareness programs should include the information on symptoms of diabetes such as polyuria and genital irritation, weight loss, and visual disturbance. ${ }^{[13]}$

\section{Awareness of health risk factor with diabetes}

Awareness of health risk factor is important for the prevention to diabetic complications. However, by and large people are not aware of the risk factors and the dangers of high risk, especially in elderly patients. ${ }^{[14]}$ The knowledge of causative factors for diabetes such as obesity, decreased physical activity, family history of diabetes, consuming sweets and other high calorie or junk foods, and mental stress are found to be very poor among the public. ${ }^{[7]}$ Further, the knowledge of risk factors is observed to be very poor among the people in Chennai, particularly mental stress and hypertension with diabetes. ${ }^{[0]}$ The lack of awareness of diabetic risk factors such as unhealthy diet, drinking alcohol, smoking, high blood pressure, laziness, irregular meals, and lack of exercise is also observed by the researchers. ${ }^{[8,15]} \mathrm{A}$ study has explored that whether the higher rates of obesity and smoking lead to depression among diabetic patients and it is found that smoking, lack of exercise, and unhealthy diet can lead to excruciating complications such as blindness, heart failure, and renal failure among patients with diabetes. ${ }^{[15]}$ The PACE study has evaluated the diabetes awareness program in Chennai and found that the awareness program has increased the healthy eating and physical activity and reduced or cessation of smoking or other forms of tobacco consumption. ${ }^{[12]}$ 


\section{Knowledge of complications with diabetes}

In general, people are not aware of the diabetes risk factors and emerging diabetes complications. In India, $41 \%$ of patients were unaware of health being affected by diabetes and only $<30 \%$ diabetic patients knew about complications related to kidneys, eyes, and nerves due to diabetes. ${ }^{[14]} \mathrm{It}$ is estimated that 40 million people in India have diabetes with different comorbidities. Out of this, at least 7 million are with retinopathy, 0.8 million with nephropathy, 10.4 million with neuropathy, 8.5 million with CVDs, and 2.5 million with peripheral vascular diseases. The prevalence of complications is much higher because of poorer control of diabetes and lack of access to health-care facility and lack of awareness. ${ }^{[14]}$ PACE project in Chennai has increased the awareness of condition of diabetes, complications of diabetes, particularly related to the eyes, kidneys, heart, and feet problem, and prevention of diabetes and ways to prevent it. ${ }^{\left[{ }^{[9]}\right.}$ It is stated that the PACE program can serve as useful model for recently launched National Programme for Prevention and Control of Diabetes, Cardiovascular Disease and Stroke by Health Ministry, Government of India. ${ }^{[12]}$

\section{Health-care practices of diabetic patients}

As proper health-care practices among diabetic patients are less in India, they are faced with health-related risks and complications. Researchers have suggested the following areas for the prevention and management of diabetes: nutritional management; physical activity; medication; monitoring blood glucose; and preventing, detecting, and treating acute and chronic complications. They have also suggested that effective self-management will contribute to long-term, higher-order outcomes such as control of glycemic blood pressure, cholesterol, and complications. ${ }^{[10]}$ However, in India, more than half of the diabetic patients do not exercise regularly. ${ }^{[8]}$ It is found that $4 \%$ of diabetic patients were on diet therapy, 54\% were receiving oral antidiabetic agents, $22 \%$ were receiving insulin, and $20 \%$ were a combination of insulin and oral medication therapy in India. ${ }^{[14]}$ More than half of the patients use oral medication than insulin and diet therapy for control of diabetes. ${ }^{[1]}$ Approximately one-quarter of patients in India did not receive any hypoglycemic agents, more than half of diabetic patients use oral medicine, and more than one-quarter of patients received insulin alone or in addition to oral agents. ${ }^{[15]}$ Importance of home-based activities and self-management such as healthy eating, exercise, medication adherence, blood glucose testing, and foot checks for diabetic patients are emphasized by the researchers. ${ }^{[15]}$

\section{Barriers in awareness of diabetes}

Researchers have identified several barriers in India for creating awareness regarding diabetes in the society. Poor economic status, lack of accessibility to health services, and inadequate follow-up are the barriers of diabetes identified. ${ }^{[14]}$ Further, the traditional beliefs are also the barriers for creation of awareness of diabetes at community level..$^{[7]}$ Medication costs, depression, and chronic pain as well as more general psychosocial problems can pose significant barriers to diabetes self-management. ${ }^{[10]}$

\section{TYPES OF COMORBIDITIES AMONG PEOPLE WITH DIABETES}

Researchers have just beginning to define challenges of diabetes and its complications. As the proportion of diabetic patients with multimorbidity continues to rise, the problem of integrating their care is the one that we cannot afford to ignore. ${ }^{[16]}$ Diabetes is strongly associated with both microvascular and macrovascular complications. Approximately one-third to one-half of diabetic patients are with these complications. ${ }^{[17]}$ In India, the urban-rural differences in the prevalence of diabetes indicate a major role of urbanization or urban lifestyle in the causation of disease. Indians are also susceptible to the major complications related to diabetes such as CVDs, nephropathy, and retinopathy. ${ }^{[18]}$

\section{Microvascular complication Retinopathy}

Retinopathy is a change in the small blood vessels found in the back of the eyes, which occurs mainly after puberty. ${ }^{[19]}$ Diabetic retinopathy can affect the peripheral retina, the macula, or both and is a leading cause of visual disability and blindness in people with diabetes. ${ }^{[17]}$ Retinopathy complication is found in one-fourth of the population with Type 2 diabetes and almost 10\% with Type 1 diabetes in Sub-Saharan Africa. ${ }^{[20]}$ Poor blood sugar control, hypertension, and a higher body mass index (BMI) are significant factors for the development of retinopathy complications with diabetes. ${ }^{[17]}$

\section{Cardiovascular complication}

Heart failure is a condition that occurs slowly over time. Heart failure occurs after an injury to the heart muscle, usually caused by uncontrolled high blood pressure, a heart attack, or a heart valve that does not work properly. The weakened heart muscle has to work overtime to keep up with the body's demands, which can leave a person tired. ${ }^{[19]}$ Cardiovascular mortality rate was observed to be higher among those with diabetes. American Diabetes Association and American Heart Association have identified the progression of high-risk CVDs with diabetes. When a person is diagnosed with diabetes for 10 years, the risk factors are found to be old age, hypertension, and increased cholesterol level. ${ }^{[21]}$ Among Northern Italians, for those with diabetes, heart 
failure was 5 times higher than the other comorbidities. ${ }^{[22]}$ South Asian in Newcastle report significantly lower level of habitual physical activity than Europeans. This is likely to contribute to the higher level of diabetes and cardiovascular risk in South Asian population. ${ }^{[23]}$

\section{Nephropathy}

When blood sugar level is high, sugar is passed into the urine, leading to higher pressure in the kidney filtering system. This may lead to change in the small blood vessels of the kidney. This increased pressure causes damage to the filtering system so that some proteins start leaking through the filter and appear in the urine. ${ }^{[19]}$ The risk factors of diabetic nephropathy are genetic susceptibility, more than 10-year duration of diabetes, unbalanced BMI, high blood pressure, and poor glycemic control and lack of protein intake in food. ${ }^{[24,25]}$ Diabetic nephropathy is found to cause chronic renal failure in $30 \%$ of diabetic patients in India. ${ }^{[2]}$

\section{Macrovascular complications}

Joint Problem (Rheumatology)

The joint problems can occur in the leg, finger, and every part of joints in the body when the diabetic suffers with high sugar level. ${ }^{[19]}$ Joint problem disorder which represents intrinsic complications of diabetes includes diabetic muscle infarction, Charcot joint, claw toe, rocker bottom sole, and limited joint mobility. A study in North West India shows the higher prevalence of various rheumatologic manifestations among diabetics. ${ }^{[2]}$ The joint problem is very common with diabetics and the associated risk factors are poor glycemic control, duration of diabetes for more than 5 years, BMI, and old age of the patients. ${ }^{[26,27]}$

\section{Foot problem}

Foot unclear is the very common complication of diabetes. In India, approximately $15 \%$ of diabetic population suffers from unclear foot complications. ${ }^{[28]}$ Foot problem usually occurs in older adults and if footsore does not heal well, it is a sign of infection. It is related to neuropathy complication and reason is high sugar level. ${ }^{[19]}$ Sociobehavioral risk factors affect foot unclear among the diabetic patients such as low literacy level, treatment by quacks, inadequate foot care, a habit of walking barefoot, smoking, and alcoholism. ${ }^{[29]}$ The risk factors are lack of awareness, depression, duration of diabetes, other complications, poor glycemic control, and the increase in BMI. ${ }^{[2]}$ The researchers have advocated relaxation modalities such as listening to music, being tender and compassionate, and promotion of yoga. ${ }^{[22]}$

\section{Stroke}

Stroke among diabetes has increased in both urban and rural part of India. ${ }^{[14,30]}$ Studies indicate that old age, duration with diabetes, tobacco use, smoking habits, obesity with high waist and hip ratio, high blood pressure, low consumption of fruits and vegetables, sedentary lifestyles and psychosocial stress, and low physical activity are important determinants of stroke complication with diabetes. ${ }^{[30-32]}$ These risk factors have increased substantially over the past 50 years, and to control further escalation, it is important to prevent them. National level interventions such as increasing tobacco taxes, promotion of healthy foods, reduction of salt in processed foods, and better urban design to promote physical activity are suggested by the researchers to have a wide short-term impact. ${ }^{[3]}$

\section{QUALITY OF LIFE WITH DIABETES}

Quality of life is related to physical, social, and mental health status of diabetic patients. The quality of life of diabetic patients is generally measured using Short-Form (SF) scale. ${ }^{[33]}$ In medical history and disease severity status, the respondents diagnosed with diabetes for a long time and suffer from different types of comorbidities indicate that diabetic patients are having worst quality of life. ${ }^{[34]}$

Demographic factors and quality of life with diabetics Studies have analyzed the relationship between gender and quality of life among diabetes patients. Higher quality of life is found among diabetic male patients than among diabetic female patients ${ }^{[35-37]}$ due to less physical activity, high obesity, and poor socioeconomic condition of women than men. ${ }^{[20]}$ A study has found poor quality of life among older diabetic patients than the younger diabetic patients in India. ${ }^{[35]}$ The reasons are long duration of diabetes, higher values of $\mathrm{HbA}_{1 \mathrm{C}}$, and presence of different types of comorbidities with elderly diabetic. ${ }^{[38]}$ Studies have also observed the relationship between health-related quality of life and marital status of diabetes patients. Separated and divorced individuals with diabetes generally experiencing lower level of quality of life than married and single diabetic patients. ${ }^{[37,38]}$

\section{Comorbidities and quality of life with diabetics}

Those diabetic patients with complications such as insulin therapy, obesity, and different types of microvascular and macrovascular complication are with lower quality of life than those diabetic patients without complications. ${ }^{[39]}$ Based on health utility index, those patients with Type 2 diabetes have a substantially decreased quality of life in association with symptomatic complication such as heart failure and depression. ${ }^{[40]}$ Relationship between quality of life and association with different types of comorbidities of diabetic patients based on SF 36 scale shows that those diabetic patients with hypertension have better quality 
of life than those with heart disease and depression. ${ }^{[41]}$ The same hospital-based cross-sectional study in 2006 in New Delhi using SF 36 scale to measure quality of life of diabetic subjects aged $\geq 20$ years found that the females had a significantly poorer quality of life than males. Poor scores in the quality of life domains were significantly associated with lower socioeconomic status, lesser education, and lesser habitual physical activity of diabetes patients in Delhi. ${ }^{[4]}$

\section{CONCLUSION}

The review of awareness, comorbidities, and quality of life of diabetes patients in India shows that diabetes patients have lack of awareness about diabetes risk factors. Lack of awareness about risk factors leads to the complications such as microvascular and macrovascular comorbidities among the diabetes patients. The diabetes patients in India are having low quality of physical, mental, and social life. The awareness about diabetes prevention and management should be increased through disease management programs, trained peers and community health workers, and community-based programs.

\section{Financial support and sponsorship}

Nil.

\section{Conflicts of interest}

There are no conflicts of interest.

\section{REFERENCES}

1. World Health Organization. Global Status Report on Noncommunicable Diseases 2014: Attaining the Nine Global Noncommunicable Diseases Targets; A Shared Responsibility. Geneva: World Health Organization; 2014.

2. Government of India. Annual Report to the People on Health. New Delhi: Ministry of Health and Family Welfare; 2011.

3. Rekha S. Assessment of Glycemic Status and Expenditure Incurred in Diabetic Subjects in Urban Field Practice Area of KIMS, Bangalore. Bangalore: Kempegowda Institute of Medical Sciences; 2012.

4. Government of India. Morbidity, Health Care and the Condition of the Aged. New Delhi: National Sample Survey Organization, Ministry of Statistics and Programme Implementation; 2004.

5. World Health Organization. Diabetes Action Now. Geneva: World Health Organization, International Diabetes Federation; 2004.

6. Alwan A, Armstrong T, Cowan M, Riley L. Noncommunicable Diseases: Country Profiles 2011. Geneva: World Health Organization; 2011.

7. Mohan D, Raj D, Shanthirani CS, Datta M, Unwin NC, Kapur A, et al. Awareness and knowledge of diabetes in Chennai - The Chennai Urban Rural Epidemiology Study [CURES-9]. J Assoc Physicians India 2005;53:283-7.

8. Wee HL, Ho HK, Li SC. Public awareness of diabetes mellitus in Singapore. Singapore Med J 2002;43:128-34.

9. Somannavar S, Lanthorn H, Deepa M, Pradeepa R, Rema M, Mohan V. Increased awareness about diabetes and its complications in a whole city: Effectiveness of the "prevention, awareness, counselling and evaluation" [PACE] Diabetes Project [PACE-6]. J Assoc Physicians India 2008;56:497-502.
10. Funnell MM, Brown TL, Childs BP, Haas LB, Hosey GM, Jensen B, et al. National standards for diabetes self-management education. Diabetes Care 2009;32:S87-94.

11. Romm FJ, Hulka BS. Care process and patient outcome in diabetes mellitus. Med Care 1979;17:748-57.

12. Somannavar S, Lanthorn H, Pradeepa R, Narayanan V, Rema M, Mohan V. Prevention awareness counselling and evaluation (PACE) diabetes project: A mega multi-pronged program for diabetes awareness and prevention in South India (PACE- 5). J Assoc Physicians India 2008;56:429-35.

13. Singh BM, Prescott JJ, Guy R, Walford S, Murphy M, Wise PH. Effect of advertising on awareness of symptoms of diabetes among the general public: The British Diabetic Association Study. BMJ 1994;308:632-6.

14. Joshi SR, Das AK, Vijay VJ, Mohan V. Challenges in diabetes care in India: Sheer numbers, lack of awareness and inadequate control. J Assoc Physicians India 2008;56:443-50.

15. Lin EH, Katon W, Von Korff M, Rutter C, Simon GE, Oliver M, et al. Relationship of depression and diabetes self-care, medication adherence, and preventive care. Diabetes Care 2004;27:2154-60.

16. Cade WT. Diabetes-related microvascular and macrovascular diseases in the physical therapy setting. Phys Ther 2008;88:1322-35.

17. Ramachandran A, Snehalatha C, Viswanathan V. Burden of type-2 diabetes and its complications-the Indian scenario. Curr Sci 2002;83:1471-6.

18. Peter CH. First Book for Understanding Diabetes. Denver: Barbara Davis Center for Childhood Diabetes, University of Colorado Denver; 2007. Available from: http://www.ucdenver.edu/academics/ colleges/medicalschool/centers/BarbaraDavis/Documents/ book-firstbook/firstbook22.pdf. [Last accessed on 2016 Oct 16].

19. Mbanya JC, Motala AA, Sobngwi E, Assah FK, Enoru ST. Diabetes in Sub-Saharan Africa. Lancet 2010;375:2254-66.

20. Buse JB, Ginsberg HN, Bakris GL, Clark NG, Costa F, Eckel R, et al. Primary prevention of cardiovascular diseases in people with diabetes mellitus: A scientific statement from the American Heart Association and the American Diabetes Association. Diabetes Care 2007;30:162-72.

21. Casiglia E, Zanette G, Mazza A, Donadon V, Donada C, Pizziol A, et al. Cardiovascular mortality in non-insulin-dependent diabetes mellitus. A controlled study among 683 diabetics and 683 age- and sex-matched normal subjects. Eur J Epidemiol 2000;16:677-84.

22. Hayes L, White M, Unwin N, Bhopal R, Fischbacher C, Harland J, et al. Patterns of physical activity and relationship with risk markers for cardiovascular disease and diabetes in Indian, Pakistani, Bangladeshi and European adults in a UK population. J Public Health Med 2002;24:170-8.

23. Viswanathan V. Prevention of diabetic nephropathy: A diabetologists perspective. Indian J Nephrol 2004;14:157-62.

24. Otu HH, Can H, Spentzos D, Nelson RG, Hanson RL, Looker HC, et al. Prediction of diabetic nephropathy using urine proteomic profiling 10 years prior to development of nephropathy. Diabetes Care 2007;30:638-43.

25. Agrawal RP, Gothwal S, Tantia P, Agrawal R, Rijhwani P, Sirohi P, et al. Prevalence of rheumatological manifestations in diabetic population from North-West India. J Assoc Physicians India 2014;62:788-92.

26. Mathew AJ, Nair JB, Pillai SS. Rheumatic-musculoskeletal manifestations in type 2 diabetes mellitus patients in South India. Int J Rheum Dis 2011;14:55-60.

27. Shahi SK, Kumar A, Kumar S, Singh SK. Prevalence of diabetic foot ulcer and associated risk factors in diabetic patients from North India. J Diabet Foot Complications 2012;4:83-91.

28. Bajwa SJ, Anand S, Singh A. Social-behavioral, clinical and anesthetic concern associated with diabetic foot amputation in a tertiary care institute of North India. J Social Health Diabetes 2015;3:120.

29. Gupta R, Joshi P, Mohan V, Reddy KS, Yusuf S. Epidemiology and causation of coronary heart disease and stroke in India. Heart 2008;94:16-26. 
30. Barrett-Connor E, Khaw KT. Diabetes mellitus: An independent risk factor for stroke? Am J Epidemiol 1988;128:116-23.

31. Wang SH, Kang YC, Wang CC, Wen MS, Hung KC, Wang CY, et al. Annual atrial tachyarrhythmia burden determined by device interrogation in patients with cardiac implanted electronic devices is associated with a risk of ischaemic stroke independent of known risk factors. Eur J Cardiothorac Surg 2015;47:840-6.

32. Ware JE, Snow KK, Kolinski M, Gandeck B. SF-36 Health Survey Manual and Interpretation Guide. Boston, MA: New England Medical Centre, The Health Institute; 1993.

33. Glasgow RE, Ruggiero L, Eakin EG, Dryfoos J, Chobanian L. Quality of life and associated characteristics in a large national sample of adults with diabetes. Diabetes Care 1997;20:562-7.

34. Mehta Z, Cull C, Stratton I, Yudkin J. Quality of life in type-2 diabetic patients is affected by complications but not by intensive policies to improve blood glucose or blood pressure control (UKPDS 37). Diabetes Care 1999;22:1125-36.

35. Alavi NM, Ghofranipour F, Ahmadi F, Emami A. Developing a culturally valid and reliable quality of life questionnaire for diabetes mellitus. East Mediterr Health J 2007;13:177-85.
36. Weiner S, Neugehauer EA. Quality of life of diabetic patients with medical or surgical treatment. Nutr Hosp 2013;28 Suppl 2:66-77.

37. Jacobson AM, Braffett BH, Cleary PA, Gubitosi-Klug RA, Larkin ME; DCCT/EDIC Research Group. The long-term effects of type 1 diabetes treatment and complications on health-related quality of life: A 23-year follow-up of the Diabetes Control and Complications/Epidemiology of Diabetes Interventions and Complications cohort. Diabetes Care 2013;36:3131-8.

38. Redekop WK, Koopmanschap MA, Stolk RP, Rutten GE, Wolffenbuttel BH, Niessen LW. Health-related quality of life and treatment satisfaction in Dutch patients with type 2 diabetes. Diabetes Care 2002;25:458-63.

39. Wexler DJ, Grant RW, Wittenberg E, Bosch JL, Cagliero E, Delahanty L, et al. Correlates of health-related quality of life in type 2 diabetes. Diabetologia 2006;49:1489-97.

40. Rubin RR, Peyrot M. Quality of life and diabetes. Diabetes Metab Res Rev 1999;15:205-18.

41. Gautam Y,Sharma A,Agarwal A,BhatnagarM,Trehan RR. A cross-sectional study of QOL of Diabetic Patients at Tertiary Care Hospitals in Delhi. Indian J Community Med 2009;34:346-50. 